\title{
An Exploratory Assessment of Codependency in Student-Athletes
}

\author{
By Aaron Livingston* \\ Chevelle Hall ${ }^{\dagger}$ \\ Gloria Ross
}

The purpose of this study was to examine social factors that may contribute to assessed level of co-dependency in student-athletes attending Historically Black Colleges and Universities. The relationships between selected demographic variables and assessed co-dependency scores were investigated. The study had a forty-six percent (46\%) response rate. Three hundred seventy-four (374) student-athletes out of eight-hundred (800) participated in the study. Out of the 374 student-athletes that responded to the investigative questionnaire, 211 (56.4\%) were male and 163 (43.6\%) were female. A One-Way ANOVA was performed to test the differences between the specific sport played and Independent Sample t-Tests were performed to test the differences between, revenue versus non-revenue sports. Co-dependency was measured by the Friel Adult Child/Co-dependency Assessment Inventory; the survey was offered to student-athletes of all ethnic groups and collegiate academic classes at the individual institutions.

\section{Introduction}

In recent years, athletic department personnel have increasingly become interested in the role of competitive sport involvement in the development of the perceptions, attitudes, and behaviors of student-athletes (Ryska, 2002; Berry \& Howe, 2002; Hausenblas \& Mack, 1999; Smith \& Stewart, 2003). These perceptions, attitudes, and beliefs have been linked to co-dependent behaviors, which include, but are not limited to eating disorders, physique anxiety, sexual aggression, and identity crises (Hausenblas \& Mack, 1999; Ryska, 2002; Smith \& Stewart, 2003). The health of the student-athlete should be a central concern for both intercollegiate athletic departments and universities. The pressure to develop responsible and civic-minded studentathletes, coupled with the pressure to maintain a competitive edge, place the coaches and athletic administrators in a very difficult situation. Therefore, it is essential that guidelines for the cognitive, mental, social, and emotional development of the student-athlete be addressed.

The ability to identify co-dependent characteristics is vitally important and should be a necessary function of any athletic department. Ideally, the process of identifying and isolating Co-dependency among student-athletes would be a

\footnotetext{
${ }^{*}$ Graduate Coordinator, Sport Administration, Hampton University, USA.

${ }^{\dagger}$ Associate Professor - Bethune Cookman University, USA.

* Associate Professor - Mississippi Valley State University, USA.
} 
fundamental aspect of the developmental process of the holistic student-athlete. Coaches and athletic administrators should address the developmental process of co-dependency, both ethically and critically, and evaluate student-athletes and coaching staffs accordingly. The lack of data concerning co-dependency that exists and the absence of guidelines to establish the extent, to which student-athletes possess codependency, indicate that a systemic approach for addressing this problem is necessary.

This research study addresses previous unknown Co-dependency issues existing among student-athletes at a Historically Black College and University Division I Intercollegiate Athletic Institutions. The research provides intercollegiate athletic departments and coaches with valuable information that can be used to develop intervention programs to combat co-dependent behaviors experienced by student-athletes. In an effort to understand the development of these cognitive disorders athletic administrators and coaches must look at where the disconnect beings. Some researchers suggest that student-athletes are socialized differently from the traditional student.

\section{Social Learning Theory}

Social Learning Theory suggests that people learn from one another, via observation, imitation, and modeling (Bandura, 1977). The theory has often been called a bridge between behaviorist and cognitive learning theories because it encompasses attention, memory, and motivation (Bandura, 1997). This theory is applicable to student-athletes because they are placed in groups in which they learn through observing others' behavior, attitudes, and outcomes of those behaviors. Bandura (1997) explains that most human behavior is learned observationally through modeling: from observing others, one forms an idea of how new behaviors are performed, and on later occasions this coded information serves as a guide for action. This is a very important point in understanding why co-dependency exists among student-athletes because student-athletes also learn from one another, via observation, imitation, and modelling. By observing teammates and coaches, studentathletes form ideas of how to behave and perform, and through competition they code information and it serves as a blueprint for competition. Social learning theory explains human behavior in terms of continuous reciprocal interaction between cognitive, behavioral, and environmental influences Bandura (1986). Bandura (1986) farther explains that there are four conditions that are necessary for effective modelling to occur; they are attention, retention, reproduction, and motivation. Attention refers to various factors that increase or decrease the amount of attention one pays to something.

Attention includes uniqueness, affective valence, frequency, difficulty, and functional value. The daily routine of student-athletes creates a unique situation which requires them to affectively divide their attention between being a student and being an athlete. Affective valence deals how people access stimuli that produce emotional highs and lows; these emotional responses help them to 
determine whether to approach or avoid a situation. Students-athletes model affective valence in the classroom by demonstrating behavior that a traditional student may attach negative consequences. For example, student-athletes are forced to deal with travel schedules, practice schedules and athletic competitions that consistently interrupt class attendance and study habits. The traditional students are not exposed to the rigors of travel schedules, practices, and athletic competitions. Bandura (1986) identifies frequency how often a person is exposed to factors that affect attention. The frequency of practice, travel, meetings, and competitions that student-athletes attend are far greater than that of traditional students.

Bandura (1986) references complexity as various factors that affect attention. The demands of athletic competition add a level of complexity to the collegiate experience that the tradition student is not exposed to (Danish, 1983). The final component of attention is functional value, which refers to the various factors that affect a person's levels of attention. An example from the student-athlete perspective of functional value would be how student-athletes are affected by the transition from being a traditional student in the classroom and transitioning to an athlete on the field of completion. This transition requires a physical and a mental; it requires the individual to now divide one's thinking process (Nakken, 1996). This second condition necessary for effective modeling to occur is retention Bandura (1986). He describes attention as the memorization of details which include symbolic coding, mental images, cognitive organization, symbolic rehearsal, motor rehearsal. Student-athletes are forced to retain information from two different perspectives. From the traditional student perspective retention is displayed in the form of class activities, presentations, note taking, and exams. For the student-athlete retention comes in the form of physical techniques, memorizing the playbook, executing play, and performing at high levels during competitions.

The third condition necessary for effective modeling to occur is reproduction, Bandura (1986) discusses reproduction in terms of reproducing an image, which includes physical capabilities, and self-observation of reproduction. For example, to traditional student these descriptions may be illustrated in taking notes, study habits, and exam performance. Now for the student-athlete, the same set of descriptions can be illustrated through physical performance assessments, film sessions, and practice session. Once again, this requires the student-athlete to make yet another transition. Finally, the fourth condition necessary for effective modeling to occur is motivation. Bandura (1986) explains motivation as having a good reason to imitate. For example, the traditional student understands that a classroom has a set of rules in which they have to adhere too. These rules are the motivating factors that influence the traditional students' behavior. Athletic competitions compiles the rules of the traditional student with the challenges of performing at the highest level of athletic competition and maintaining the limits set by the rules that govern sport. This section discusses in detail the foundation of social learning which explains how individuals socialize according to how people learn from one another. As noted, this theory has often been called a bridge between 
behaviorist and cognitive learning theories because it encompasses attention, memory, and motivation of one's self. If an individual fails to or struggles to make this transition the end result can lead to co-dependency (Friel \& Friel, 1988).

\section{Codependency}

Many definitions seek to describe codependency. Co-dependency has been defined as an extreme focus on relationships, caused by a stressful family background (Fischer et al., 1991). Co-dependency has now become a common household term. From the extensive self-help literature to the talk show circuit, co-dependency is a construct familiar to many Americans. Originally, the term was used to describe the dysfunctional relationship between a spouse and his or her alcoholic counterpart (Lindley et al., 1999). Hemfelt et al., (1989) claimed that as many as one in four Americans are codependent. Whitfield (1991) regarded codependency as a "disease" of lost selfhood and offered 23 possible definitions of the condition, claiming that varieties of definitions are advantageous. Literature defines co-dependency in a variety of ways, even as broadly as "an addiction to people, behaviors, or things" (Hemfelt et al., 1989, p. 11). Often, co-dependency is a common reaction to a stressful situation. In the case of the student-athlete, it may be manifested as inappropriate behavior, including personality disorders and addictive behaviors.

In addition to other definitions, co-dependency refers to a chemical response or change in the brain brought on by very specific behaviors (Cruse \& Cruse, 1990). Co dependency has a tendency to become compulsive, it increases in frequency, intensity, and variety as it continues to develop. Codependent individuals develop a tolerance to the original benefits of the coping behaviors. Eventually, most compulsive mood changing behaviors and mood changing substances become engrained and disabling because the co-dependent individual does not feel that he/she is able to control or stop the compulsion, but has the illusion of being in control (Friel \& Friel, 1988).

However, in the discussion of co-dependency and co-dependent individuals an overload of specifics can increase confusion unless we have a framework to understand the whole (Cruse \& Cruse, 1990). According to Cruse \& Cruse (1990) major strides have been made over the last decade in the field of addictive disease. One of the most important changes has involved the increased awareness of co-dependency and the emergence of a co-dependency field. Included in the changes are avenues to convince co-dependent individuals to accept treatment; educating co-dependents' families that codependency is a family disease; and ensuring that the standards used for inpatient and outpatient programs for both addict and family members are available and readily accessible. Other key evolvements include the knowledge that there is a rise in the number of child co-dependents and the painful process involving adult-children of co-dependents. On a grand scale, these strides have been necessary as public knowledge of co-dependency largely consists of 
chemical dependencies and enabling dependencies that are formed as a basis of parent/child or husband/wife relationships.

A greater understanding of the different aspects of co-dependency allows researchers to conceptualize the term in ways that can benefit various individuals and groups within society. Cruse \& Cruse (1990) list the three dimensions of co-dependency as (1) the person or the person who becomes codependent, (2) the process which refers to the disease itself and (3) the planet or the environment in which co-dependent processes evolve or are sustained. People who demonstrate co-dependency have been afflicted with self-defeating behaviors that come from internalized emotional pain. The process by which a person can become co-dependent involves his or her own thoughts, feelings, and behaviors. The planet refers to the co-dependent person's relationships, which may be toxic and unhealthy.

\section{Addictive Behavior}

Addictive behavior can be found in all people (Nakken, 1996). It is a biproduct of co-dependency, a term developed to establish the responses and the behaviors of people living with alcoholism or substance abuse. A co-dependent refers to an individual who relies on outside sources for energy to validate him/her self. For example, a person that makes decisions solely based on the advice of others (peer pressure) can be classified as co-dependent. The codependency concept is actually very simple. A co-dependent feels that he/she cannot survive as an individual without depending on something; "once a person starts to look to an object or event for emotional stability, he or she is building the foundation of an addictive relationship with it" (p.10). The definition of addiction, which is a variation of one developed in the chemical dependency field, is as follows: addiction is a pathological love and trust relationship with an object or event. What exactly does this mean? To be pathological is to deviate from a healthy or normal condition. When someone is described as being ill, we mean that this person has moved away from what is considered "normal. The word pathological, refers to abnormal and consequently addiction is an abnormal relationship with an object or event (Nakken, 1996).

All objects have normal, socially acceptable functions: food is to nourish; gambling is for fun and excitement; drugs are to help manage pain or to overcome illness. Anyone using these objects or events in these ways would be seen as having a normal, healthy relationship with them. In an addiction, however, the addict departs from the normal and socially acceptable function of the object and sets up a pathological or abnormal relationship. The food, gambling, or drugs take on a new function: the addict develops a relationship with the event or object, hoping to get his or her needs met. This is the insanity of addiction, for people normally get emotional and intimacy needs met through a balanced combination of intimate connections with other people, themselves, their community, and with Higher Power (Nakken, 1996). 
Student-athletes are more susceptible or placed at a higher risk for addictions than traditional students place because their dual/multiple personalities as described by disorders (Hausenblas \& Mack, 1999; Ryska, 2002; Smith \& Stewart, 2003). The personality of the academic student can only exist prior to and after the engagement of the sporting event. For example, pressures from practices, games, media, and course loads present outside influences that can and will consume one's thinking process. Student-athletes are consistently confronted with the trials of physical performance and academic advancement. To perform as an elite athlete requires an individual to physically train at higher levels (Kimball \& Freysinger, 2003). Physical training is very time consuming and stressful because of the physical demands placed on the human body.

The rigors of academic success claim a very different stress than that of athletics. Academic achievements are both physically and mentally stressful. The time that an individual spends trying to develop academia demands physical stamina as well as mental conditioning. Therefore, in order to excel in both areas, a person must develop two very different ways of thinking (Kimball $\&$ Freysinger, 2003). The student-athlete becomes trapped in a cycle because he/she is now co-dependent upon outside sources that will create stress and will require clinical treatment. Clinical treatment programs have been used to rehabilitate addicts, people who have surrendered themselves to obsessive behaviors (Hausenblas \& Mack, 1999; Ryska, 2002; Smith \& Stewart, 2003). Co-dependent behavior closely relates to addictive behavior because of the unconsciousness that exists in addictions. This unconsciousness experienced by addicts is developed from negativity, mistrust of others, and hopelessness. Addicts seem to misunderstand that there is nothing wrong with them; they forget their natural feelings and beliefs. In their unconscious thinking, their feelings and beliefs tend to take control of their lives. This behavior totally and completely consumes their actions. Addicts begin to trust the addictive mood change caused by their addiction to an object or event because it is consistent and predictable. "This seductive part of addiction alludes to the propensity of the addicts, drug addicts, gamblers and even food addicts, to experience predictable mood changes when they yield to cravings to satisfy that addiction (Nakken, 1996).

\section{Intercollegiate Athletics}

Intercollegiate athletics have become a significant aspect of American higher education (Duderstatdt, 2000; Focus on Intercollegiate Athletics, 1995; Shulman \& Bowman, 2001; Sperber, 1990, 2000; Telander, 1996; Thelin, 1994). Because of rising significance and visibility, collegiate athletes have received more attention from university/college administrators and athletic administrators than ever before. The National Collegiate Athletic Association distributes about $\$ 1$ billion dollars annually to student-athletes. Athletic scholarships for undergraduate student-athletes are at an all-time high in 
Division I and Division II schools. In fact, over 126,000 student-athletes receive either partial or full athletic scholarships. This is an investment for colleges and universities alike. Collegiate athletics is a power tool in the recruitment of the general student population on college campuses (Kesenne, 2006). With so much money being pledged, it should be common practice to secure such a valuable asset.

Student-athletes are unique. A student-athlete represents the special case in the collegiate experience because of a less than normal way of life (Crester \& Lombardo, 1999). The everyday experiences for student-athletes are unusual and create stresses not experienced by the traditional college students. For example, practice and game times require countless hours of preparation for athletes in addition the academic tasks they must perform. Travel schedules and team meetings force student-athletes to be at and function at higher levels as college students. These issues can and will produce constraining forces of influence commonly referred to as stress. Stress can be physical or psychological (Fuller \& Warner 2000). For student-athletes, these stressors can be physical and psychological at the same time. The stress of being an athlete as well as a student can lead to mental conditions that require clinical assessments.

The physical and mental well being of student-athletes has been addressed since the early 1900's (Eaton \& Smith, 1941). It is sad to say, however, that only a few studies about mental health issues concerning student-athletes that exist. Since billions of dollars are being generated each year from intercollegiate athletic events, the health, and particularly the mental health, of student-athletes should be a high priority. Prioritizing the mental health of student-athletes will protect the individual from developing compulsive behaviors and will minimize the frequency, intensity and variety of negative behaviors that develops as co-dependency continues to develop. Developing intervention programs to identify co-dependent traits will protect the investments of colleges and universities, as well as, produce positive and productive citizens for our communities.

To address the mental dilemmas that the student-athlete may be experiencing, we must find the origins of these problems that incidentally usually begin in the early stages of life. Simply stated, who an individual is comes from what that individual experiences in their life trajectory (Bandura, 1986). Life experiences automatically produce stressors that individuals are forced to deal with on a day-to-day basis. The consistent pressures of everyday life are enough to warrant psychological evaluations; for student-athletes these pressures are more extreme because their life styles are typically more demanding than those of traditional students (Crester \& Lombardo, 1999). The lives of student-athletes, in a sense, occur within dual or multiple existences. Clinicians have traditionally diagnosed dual/multiple personalities as illnesses such as schizophrenia, bipolar, and other disorders (Hausenblas \& Mack, 1999; Ryska, 2002; Smith \& Stewart, 2003). Student-athletes spend most of their time split between academics and athletics, leaving little time for individual development. This requires dual/multiple personalities to accomplish day-to- 
day tasks. Multiple personalities form the foundation of mental disorders because there is a loss-of-self that takes place (Feltz, 1988).

Personality disorders can divide one's thinking process, creating an addictive personality because there is no focus left on the individual (Nakken, 1996). Addictive behaviors are habits cycles (Friel \& Friel, 1988). These are things become unconsciously patterned and habitual. We are not aware that we are functioning in patterns until we are diagnosed. Personality disorders are dysfunctions in the state of being of a person; an individual loses his/her self in their own life experiences. This "loss-of-self", creates an identity crisis. Who am I? What am I doing? Why am I doing this? These are questions commonly asked by individuals who are struggling with a reconnection to reality. This reconnection must be attained through a process. Athletic administrators and coaches must recognize and identify these personality disorders because they are problems caused by addictive behaviors. In effort to understand the development of these cognitive disorders athletic administrators and coaches must look at where the disconnection beings. Some researchers suggest that student-athletes are socialized differently from the traditional students.

\section{Instrumentation and Psychometrics}

The Friel Adult Child/Co-dependency Assessment Inventory (Friel, 1985) has been developed and used since its creation in numerous research studies and was selected for use in this study. It was designed and developed on theory and clinical practice from working with dysfunctional families. The intent is to help identify issues of adult children of dysfunctional families and assesses codependency traits. Friel \& Friel (1985) have determined the existence of symptoms to be core symptoms, as has been used to define co-dependency. Isham-Colvard (1998) reported that the Friel (1985) Co-dependency Assessment Inventory (CAI) was used as the measure of co-dependency in $62.4 \%$ of the studies reviewed in her meta-analysis of the literature. Friel \& Friel (1987) used fairly homogenous samples (significant others who were participating in family programs of a chemical dependency treatment center and professional counselors and therapists at a chemical-dependency treatment field) in the development of their instrument. The initial reliability figures, using the KR-20, were in the range of .83 to .85. The Friel (CAI) ranks respondents into the following levels of dependency: none, mild, moderate, or severe.

The Friel Adult Child/Co-dependency Assessment Inventory questionnaire consists of 60 true-false questions. Participants receive 1 point for every "true" response for even-numbered questions and 1 point for every "false" response for odd-numbered questions. Participants could receive a total possible score of 60 points. Scores from $0-9$ indicate no identifiable issues of co-dependency. Scores from 10 to 20 indicate mild co-dependency; scores from 21 to 30 indicate mild-moderate co-dependency; 31 to 45 indicate moderate to severe 
co-dependency and scores over 45 indicate severe co-dependency. The time required to complete the questionnaire is approximately 15 to 20 minutes.

The Friel Adult Child/Co-dependency Assessment Inventory questionnaire has been used in the college student population. In a study conducted by Crester \& Lombardo (1999) the Co-dependency Self-Inventory Scale was administered to a sample of college students and found that about half were familiar with the concept of co-dependency. The majority of students scored in the third quartile of scores, and there were no significant differences between age and ethnic groups. A greater proportion of men than women earned codependency scores in the highest two categories. Fuller \& Warner (2000) also used college students in their study of two different measures of codependency. Students who reported backgrounds of family stress in the form of an alcoholic, mentally ill, or physically ill parent had higher scores on both codependency inventories. They also found that women tended to score higher than men on the two measures.

Lindley et al. (1999) studied the relationship between co dependencies and theoretically related psychological characteristics. They found that codependency was negatively related to self-confidence, and positively related to a tendency to seek emotional support. Co-dependency was unrelated to autonomy. Springer et al. (1998) found that higher scores on the Codependency Assessment Inventory (CAI; Friel 1985) were associated with selfconsciousness, social anxiety, dysfunctional attachment, and empathic sharing of emotions.

The above studies provide empirical support for the validity and reliability of the Friel inventory and support its use in the present study. These psychometric properties, specific to the student-athlete population, will also be examined in this study for further evidence of its validity and reliability relative to use in intercollegiate athletics.

\section{Methods}

The research utilizes descriptive information to assess co-dependency in student-athletes and the extent of behaviors that may lead to increase risks of levels of co dependence. The Friel Adult Child/Co-dependency Assessment Inventory was used to assess co-dependency. This research project employs correlations and descriptive statistics to analyze the data based on two variables including specific sport and revenue status of the sport.

\section{Subjects}

The study had a forty-six percent $(46 \%)$ response rate. Three hundred seventy-four (374) student-athletes out of eight-hundred (800) participated in the study. Participants were chosen from participating Historically Black College and University Division I Intercollegiate Athletic Institutions. The 
participants were described by their specific sport activity in which they participated and whether the university considers their sport to be a revenue generating sport or not.

\section{Data Collection Procedures}

Participants for this research project were full-time student-athletes enrolled in Historically Black Division I Universities. The survey was offered to student-athletes of all ethnic groups and collegiate academic classes at the individual institutions. The recruitment and data collection procedures occurred in sequence. First, athletic directors/athletic administrators of participating universities included in the study were contacted to get permission to meet with the student-athletes at the institutions. Second, a permission form was signed by each athletic director/athetic adminstrator. In the second step, arrangements were made for the researcher to meet with student-athletes without any coaches or athletic administrators present to alleviate any feelings of pressure on the part of the participants. In step three, the researcher met with student-athletes to explain the purpose of the study and read a verbal script (consent statement) explaining the procedures, benefits of the study and potential risks.

Next it was stated that any student-athletes who did not wish to participate were free to leave the meeting and there would be no penalties whatsoever for not participating. For those who stayed, it was explained that by completing the demographic form and the Friel Adult/Child Co-dependency Assessment Inventory, they were giving their consent to participate in the study. This procedure was chosen as an alternative to obtaining actual signed written consent forms at the request of the participating athletic departments.

The primary researcher provided every student-athlete with a packet containing the Friel Adult/Child Co-dependency Assessment Inventory, the demographic questionnaire and a copy of the consent statement. In effort to protect the privacy of participants, the primary researcher was solely responsible for the distribution and collection of all survey packages containing the Friel Adult/Child Co-dependency Assessment Inventory and demographic questionnaire.

After the completion of the questionnaires, the primary researcher placed all responses in a sealed package that was not opened until the time of analysis. Data collected from the Friel Adult/Child Co-dependency Assessment Inventory and the demographic questionnaires was then entered into the statistical program SPSS version 10. A significance level of $p<.05$ and the Tukey correction was applied to the dataset. The Tukey correction procedure allows the alpha level of each individual test to be adjusted to maintain the experiment wise alpha level at $(\mathrm{p}<.05)$. The Tukey correction was chosen for this particular study because it has traditionally been applied in multiple comparison tests in studies like this. 


\section{Results}

Descriptive statistics for assessed level of co-dependency that exist between the sports of football, basketball, softball, volleyball, track, tennis, soccer, cross-country, baseball and golf student-athletes with regard to assessed co-dependency are provided in Table 1, 2, 3, and 4.One- way ANOVA was performed to test differences in assessed co-dependency with the independent variables specific sport played. Indicated in Table 1 are the mean and standard deviation results with respect to the co-dependency scores of student-athletes by their sport

Table 1. Frequency Distribution of Participants by Sport

\begin{tabular}{|l|c|c|}
\hline Sport & Number & Percent \\
\hline Football & 119 & 31.8 \\
\hline Basketball & 40 & 10.7 \\
\hline Softball & 45 & 12.0 \\
\hline Volleyball & 21 & 5.6 \\
\hline Track & 54 & 14.4 \\
\hline Tennis & 9 & 2.4 \\
\hline Golf & 10 & 2.7 \\
\hline Baseball & 43 & 11.5 \\
\hline Soccer & 13 & 3.5 \\
\hline Cross Country & 20 & 5.3 \\
\hline Total & 374 & 100.0 \\
\hline
\end{tabular}

Indicated in Table 2 are the mean and standard deviation results with respect to the co-dependency scores of student-athletes by their sport. A OneWay ANOVA was used to determine the differences between the codependency scores of student-athletes by their sport. As revealed in Table 3, a statistically significant difference was found between the co-dependency scores of student-athletes with regard to their sport at the .001 level $(\mathrm{F}=8.658$, $\mathrm{df}=9 / 364, \mathrm{p}<.001)$.

Table 2. Mean and Standard Deviation Results Regarding Co-dependent Scores by Sport Activities

\begin{tabular}{|l|c|c|}
\hline Sport Activities & Mean & SD \\
\hline Football & 28.13 & 5.25 \\
\hline Basketball & 27.03 & 6.49 \\
\hline Softball & 23.84 & 9.11 \\
\hline Volleyball & 23.33 & 9.48 \\
\hline Track & 25.11 & 6.94 \\
\hline Tennis & 26.78 & 5.87 \\
\hline Golf & 30.30 & .82 \\
\hline Baseball & 19.44 & 7.88 \\
\hline Soccer & 22.15 & 7.85 \\
\hline Cross Country & 30.20 & .89 \\
\hline
\end{tabular}


Table 3. Analysis of Variance Summary Table Regarding the Assessed Codependency Scores of Student-athletes by Sport Activitie

\begin{tabular}{|l|c|c|c|c|c|c|}
\hline $\begin{array}{l}\text { Source of } \\
\text { Variance }\end{array}$ & $\begin{array}{c}\text { Sum of } \\
\text { Squares }\end{array}$ & df & $\begin{array}{c}\text { Mean } \\
\text { Square }\end{array}$ & F & P & Eta $^{2}$ \\
\hline Between & 3541.193 & 9 & 393.466 & 8.658 & $.000 * * *$ & .176 \\
\hline Within & 16541.887 & 364 & 45.445 & & & \\
\hline Total & 20083.080 & 373 & & & & \\
***Significant at the $\mathrm{p}<.001$ level
\end{tabular}

Further data analysis employing the Tukey post hoc procedure (Table 4), reveals that football, basketball, track \& field, golf, and cross country studentathletes had significantly higher co-dependency scores than their baseball peers. Additionally, football athletes possessed significantly higher dependency scores than softball student-athletes. Also, cross country student-athletes exhibited significantly higher co-dependency scores than did those studentathletes who participated in softball and soccer. These findings farther illustrate and are consistent with (Bandura, 1997) discussion in Social Learning Theory.

These findings suggest that there is an observed relationship that exists in identifying co-dependent characteristics in student-athletes according to the sport in which they participate. This is a very important finding because it encompasses (Bandura, 1997) notations discussed in the Social Learning Theory.

The differences in the co-dependency scores of student-athletes who participate in revenue and non-revenue sports were computed using the $t$-test on independent samples. As reported in Table 5 the mean co-dependency score for student-athletes who participate in revenue sports was 28.15 ( $\mathrm{SD}=5.29)$. In comparison, the mean co-dependency score for student-athletes who participate in non-revenue sports $(t=6.55, \mathrm{df}=336.86, \mathrm{p}<.001)$ at the .001 level. Based on the aforementioned findings, student-athletes attending historically black colleges and universities who participate in revenue sports had significantly higher codependency scores than their counterparts who participate in non-revenue sports.

\section{Discussion}

Competitive balance has always been one of the major concerns of athletic administrators at all levels of team sport (Kesenne, 2006). Although the empirical research does not always confirm the importance of a balanced competition (Borland \& McDonald, 2003), it is generally accepted that an excessive imbalance in sports competitions will have a negative impact on spectator interest. The literature discusses that different measures have been proposed to improve the competitive balance; according to (Kesenne, 2006), revenue sharing has been the most controversial regulatory measure. The proposition that revenue sharing does not affect the distribution of playing talent among profit-maximizing teams has been challenged by many sports economists since the publication of Rotenberg's (1956) article and the formal proof of the proposition by Quirk and El Hodiri (1974). For this reason, it is very important to understand that co-dependency has no boundaries. It is not 
restricted to any particular sport; it doesn't discriminate; it doesn't care if a student-athlete generates revenue for the university or not.

Table 4. Tukey Results Regarding Co-Dependent scores of Student-athletes by Sport Activities

\begin{tabular}{|c|c|c|c|}
\hline FT-BB & $28.13-27.03$ & 1.11 & .996 \\
\hline FT-SB & $28.13-23.84$ & 4.29 & $.010 *$ \\
\hline FT-VB & $28.13-23.33$ & 4.80 & .078 \\
\hline FT-TR & $28.13-25.11$ & 3.02 & .160 \\
\hline FT-TE & $28.13-26.78$ & 1.36 & 1.000 \\
\hline FT-GF & $28.13-30.30$ & -2.17 & .994 \\
\hline FT-BA & $28.13-19.14$ & 8.69 & $.000 * * *$ \\
\hline FT-SO & $28.13-22.15$ & 5.98 & .072 \\
\hline FT-CC & $28.13-30.20$ & -2.07 & .961 \\
\hline BB-SB & $27.03-23.84$ & 3.18 & .477 \\
\hline BB-VB & $27.03-23.33$ & 3.69 & .576 \\
\hline BB-TR & $27.03-25.11$ & 1.91 & .939 \\
\hline BB-TE & $27.03-26.78$ & .25 & 1.000 \\
\hline BB-GF & $27.03-30.30$ & -3.28 & .935 \\
\hline BB-BA & 27.03-19.14 & 7.58 & $.000 * * *$ \\
\hline BB-SO & $27.03-22.15$ & 4.87 & .413 \\
\hline BB-CC & $27.03-30.20$ & -3.18 & .784 \\
\hline SB-VB & $23.84-23.33$ & .51 & 1.000 \\
\hline SB-TR & $23.84-25.11$ & -1.27 & .995 \\
\hline SB-TE & $23.84-26.78$ & -2.93 & .974 \\
\hline SB-GF & $23.84-30.30$ & -6.46 & .158 \\
\hline SB-BA & $23.84-19.14$ & 4.40 & .067 \\
\hline SB-SO & $23.84-22.15$ & 1.69 & .999 \\
\hline SB-CC & $23.84-30.20$ & -6.36 & $.016^{*}$ \\
\hline VB-TR & $23.33-25.11$ & -1.78 & .991 \\
\hline VB-TE & $23.33-26.78$ & -3.44 & .958 \\
\hline VB-GF & $23.33-30.30$ & -6.97 & .178 \\
\hline VB-BA & $23.33-19.14$ & 3.89 & .479 \\
\hline VB-SO & $23.33-22.15$ & 1.18 & 1.000 \\
\hline VB-CC & $23.33-30.20$ & -6.87 & .037 \\
\hline TR-TE & $25.11-26.78$ & -1.67 & 1.000 \\
\hline TR-GF & $25.11-30.30$ & -5.19 & .432 \\
\hline TR-BA & 25.11-19.14 & 5.67 & $.002 * *$ \\
\hline TR-SO & $25.11-22.15$ & 2.69 & .921 \\
\hline TR-CC & $25.11-30.20$ & -5.09 & .110 \\
\hline TE-GF & $26.78-30.30$ & -3.52 & .981 \\
\hline TE-BA & $26.78-19.14$ & 7.34 & .088 \\
\hline TE-SO & $26.78-22.15$ & 4.62 & .857 \\
\hline TE-CC & $26.78-30.20$ & -3.42 & .961 \\
\hline GF-BA & $30.30-19.14$ & 10.86 & $.000 * * *$ \\
\hline GF-SO & $30.30-22.15$ & 8.15 & .113 \\
\hline GF-CC & $30.30-30.20$ & .10 & 1.000 \\
\hline BA-SO & $19.14-22.15$ & -2.71 & .960 \\
\hline BA-CC & 19.14-30.20 & 10.76 & $.000 * * *$ \\
\hline $\mathrm{SO}-\mathrm{CC}$ & $22.15-30.15$ & -8.05 & $.028 *$ \\
\hline
\end{tabular}

FT=Football, $\quad$ TE=Tennis, $\quad \mathrm{BB}=$ Basketball, $\quad \mathrm{GF}=$ Golf, $\quad \mathrm{SB}=$ Softball, $\quad \mathrm{BA}=$ Basketball, $\mathrm{VB}=$ Volleyball, $\mathrm{SO}=$ Soccer, TR=Track, $\mathrm{CC}=$ Cross Country $* \mathrm{p}<.05, * * \mathrm{P}<.01, * * * \mathrm{p}<.001$ 
Table 5. t-Test Differences between Assessed Codependency Scores of Studentathletes with regard to Revenue Status

\begin{tabular}{|l|c|c|c|}
\hline Statistics & $\begin{array}{c}\text { Revenue } \\
(\mathrm{n}=178)\end{array}$ & $\begin{array}{c}\text { Non-Revenue } \\
(\mathrm{n}=196)\end{array}$ \\
\hline Mean & 28.15 & & 23.52 \\
\hline SD & 5.29 & & 8.20 \\
\hline SE & .40 & & .59 \\
\hline Mean Diff & & 4.64 & \\
\hline$t$ & & $6.55^{* * *}$ & \\
\hline df & & 336.86 & \\
$* * * \mathrm{p}<.000$ & \multicolumn{3}{|l}{}
\end{tabular}

The data in this study indicates that almost $75 \%$ of the student-athletes who participated exhibits co-dependent traits as classified by the Friel Adult Child/Co-dependency Assessment Inventory. Nakken (1996) proposed that student-athletes spend most of their time split between academics and athletics. Because of this, they have little time for individual development. They are susceptible to co-dependency behavior because they are forced to rely on outside sources such as teammates, coaches, and the media for energy to validate them. Nakken (1996) also suggested that student-athletes feel they cannot survive as individuals without depending on someone else. According to Nakken (1996), this leads to an addictive behavior known as co-dependency.

One of the research questions of this study addressed whether or not differences existed between the observed co-dependency scores of studentathletes by sport. The statistical analysis revealed that that football, basketball, track \& field, golf, and cross country student-athletes had significantly higher co-dependency scores than their baseball peers. Additionally, football studentathletes possessed significantly higher co-dependency scores than softball student-athletes. In addition, cross-country student-athletes exhibited significantly higher co-dependency scores than did those student-athletes who participated in softball and soccer. Another interesting finding of this study was that the codependency ratings of student-athletes who participate in revenue sports were higher than those who compete in non-revenue sports. This finding leads to several questions that may need to be explored relative to the possible pressures felt by athletes in these sports.

In the ever-changing world of collegiate athletics, the pressure to win is fuelled by the generation of revenue. Revenue sports such as football and basketball are often depended upon to supplement non-revenue sports at smaller institutions (Kesenne, 2006). The pressure to win is escalated because it is what keeps the stadiums full; it keeps the fans loyal and happy; and it also keeps tuition paid. There is no doubt that revenue sport athletes are linked to other performance pressures, which may affect academic performance, etc. 


\section{Conclusions}

The information gathered in this study can be used to help coaches and athletic administrators recognize the personality characteristics of studentathletes. Such information can also result in successful innovative prevention, intervention, and treatment programs for substance use and abuse. We have to understand that one of the main duties as defined by the profession of athletic administrators and coaches is to develop the cognitive, mental, social, and emotional health of the student-athletes. This is a vital aspect of any athletic program. Relative to the social and emotional health of student-athletes, it is necessary for athletic administrators and coaches to recognize the athletes' reactions to stress and be more aware of the common psychological concept known as co-dependency.

Co-dependency will continue to challenge mainstream theoretical notions about the nature of people and behavior. In the case of student-athletes, codependency can occur as lack of self-confidence and changes in mood states that may affect athletic performance. Self-confidence is one of the most frequently cited psychological factors thought to effect sport performance and has been a primary focus of research conducted by sport psychologists as it is considered by many to be a key factor to successful performance (Feltz, 1988). If this study were replicated on a larger population of student- athletes, the results could be different or it could reveal much more alarming results. More research is needed to make this determination.

\section{References}

Alexander, C. (1985). "The Definition of Co-Dependence," panel at the San Francisco Conference on Children of Alcoholics. The National Association for Children of Alcoholics.

Allison, S. (2004). Nurse Codependency: Instrument Development and Validation. Journal of Nursing Measurement, 12, 63-75.

Anderson, S. (1994). A critical analysis of the concept of codependency. Journal of the National Association of Social Work, 39 (6), 677-685.

“Anxiety." Def. 1. Longman Dictionary of Contemporary English. New ed. Harlow: Longman House, 1987.

Baron, R. A., \& Greenberg, (1990). Behavior in Organizations: Understanding and Managing the human side of work ( $\left.3^{r d} e d ..\right)$ Needham Heights, MA: Ally and Bacon.

Bandura, A. (1997). Self-efficacy: The exercise of control. New York: W.H. Freeman.

Bandura, A. (1986).Social Foundations of Thought and Action. Englewood Cliffs, NJ: Prentice-Hall.

Bandura, A. (1973). Aggression: A Social Learning Analysis. Englewood Cliffs, NJ: Prentice-Hall.

Bandura, A. (1977). Social Learning Theory. New York: General Learning Press.

Bandura, A. (1969). Principles of Behavior Modification. New York: Holt, Rinehart \& Winston. 
Bandura, A. \& Walters, R. (1963). Social Learning and Personality Development. New York: Holt, Rinehart \& Winston.

Borland, J., \& Macdonald, R. (2003). Demand for sport. Oxford Review of Economic Policy, 19, 478-502.

Crester, G. and Lombardo, W. (1999). Examining codependency in a college population. College Student Journal, 33 (4), 629-637.

Cruse, J., \& Wegscheider-Cruse, S., (1990). Understanding Co-Dependency. Deerfield Beach, FL.: Health Communication Inc.

Danish, S. J. (1983). Musing about personal competence: The Contributions of sport, health, and fitness. American Journal of Community Psychology, 11, 221-240.

"Depression." Def. 1. Longman Dictionary of Contemporary English. New ed. Harlow: Longman House, 1987.

Duderstadt, J. (2000). Intercollegiate athletics and the American University: A university President's perspective. Ann Arbor, MI: University of Michigan Press.

Eaton, M. \& Smith, H. (1941). The Scholastic achievement of athletes at Indiana University. Bulletin XVII of the school of education, Indiana University.

Feltz, D. (1988). Self-Confidence and Sports Performance. Exercise and Sport Sciences Reviews, 16, 423-458.

Fischer, J.L., Spann, L., \& Crawford, D.W. (1991). Measuring codependency. Alcoholism Treatment Quarterly, 8, 20-21.

Focus on Intercollegiate Athletics. (1995). Journal of College and University Law, 22, $1-74$.

Friel, J. (1985 May/June). Co-Dependency Assessment Inventory: A preliminary research tool. Focus on the Family and Chemical Dependency, 8(3), p. 20-21.

Friel, J.C. and Friel, L.D., (1987, Nov/Dec). Uncovering our frozen feelings. Focus Group, p.10-12.

Friel, J.C. and Friel, L.D. (1988). Adult children: The secrets of dysfunctional families. Pompano Beach, FL: Health Communications.

Friel, L., Friel, J., R Subby, R. (1984). Co-dependence and the Search for Identity. Pompano Beach, Florida: Health Communications, Inc.

Fuller, J. and Warner, R. (2000). Family stressors as predictors of codependency. Genetic, Social \& General Psychology Monographs, 126 (1). 5-22.

Hausenblas, H.A., \& Mack, D.E. (1999). Social Physique Anxiety and Eating Disorder Correlates Among Female Athletic and Non-athletic Populations. Journal of Sport Behavior, 22, 502-512.

Hemfelt, R., Minirth, F., \& Mejer, P. (1989) Love is a choice. Recovery for codependent relationships. Nashville, TN: Thomas Nelson Publishers.

Kesenne, S. (2006). Competitive Balance in Team Sports and the Impact of RevenueSharing. Journal of Sport Management, 2006, 20, 39-5.

Kimball, A. \& Freysinger, V. J. (2003). Leisure, Stress, and Coping: The Sport Participation of collegiate Student-Athletes. Leisure Sciences, 25, 115-141.

Lindley, N. R., Giordano, P. j., Hammer, E. D. (1999). Codependency: Predictors and psychometric issues. Journal of Clinical Psychology, 55, 59-64.

Nakken, C. (1996). The Addictive Personality: understanding the addictive process and complusive behavior. Center City, MN: Hazelden Foundation and Educational Services.

Quirk, J., \& El Hodiri, M. (1974). The economic theory of a professional sports league. In R. Noll (Ed.), Government and the sport business (pp. 33-88). Washington DC: Brookings Institution.

Rottenberg, S. (1956). The baseball players' labor market. Journal of Political Economy, 64, 242-258. 
Ryska, T.A. (2002). The Effects of Athletic Identity and Motivation Goals on Global Competence Perceptions of Student-Athletes. Child Study Journal, 32 (2), 109112.

Shulman, J., \& Bowen, W. (2001). The game of life: College sports and educational values. Princeton, NJ: Princeton University Press.

Smith, D., \& Stewart S., (2003). Sexual Aggression and Sports Participation. Journal of Sport Behavior. 26, 384-387.

Sperber, M. (1990). College sports inc.: The athletic department vs. the university. New York, NY: Henry Holt and Company.

Sperber, M. (2000). Beer and circus: How big-time college sports is crippling undergraduate education. New York, NY: Henry Holt and Company.

Telander, R. (1996). The hundred yard lie: The corruption of football and what we can do to stop it Urbana: Urbana, University of Illinois Press.

Thelin, J. (1994). Games Colleges Play: Scandal and reform in intercollegiate athletics Baltimore: John Hopkins University Press.

Whittfield, C.L., (1991). Co-dependence: Healing the human condition. Deerfield Beach, FL: Health Communication, Inc. 
